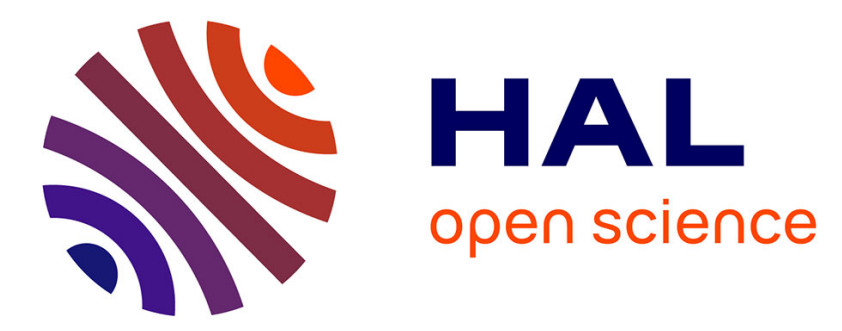

\title{
Lanthanide complexes as imaging agents anchored on nano-sized particles of boehmite
}

Estefania Delgado-Pinar, M. Teresa Albelda, Juan C. Frias, Olga Barreiro, Emilio Tejera, Vojtech Kubicek, Luis J. Jimenez-Borreguero, Francisco Sanchez-Madrid, Éva Tóth, Javier Alarcon, et al.

\section{To cite this version:}

Estefania Delgado-Pinar, M. Teresa Albelda, Juan C. Frias, Olga Barreiro, Emilio Tejera, et al.. Lanthanide complexes as imaging agents anchored on nano-sized particles of boehmite. Dalton Transactions, 2011, 40 (24), pp.6451-6457. 10.1039/c1dt10389j . hal-00614888

\section{HAL Id: hal-00614888 \\ https://hal.science/hal-00614888}

Submitted on 29 Sep 2021

HAL is a multi-disciplinary open access archive for the deposit and dissemination of scientific research documents, whether they are published or not. The documents may come from teaching and research institutions in France or abroad, or from public or private research centers.
L'archive ouverte pluridisciplinaire HAL, est destinée au dépôt et à la diffusion de documents scientifiques de niveau recherche, publiés ou non, émanant des établissements d'enseignement et de recherche français ou étrangers, des laboratoires publics ou privés. 


\title{
Lanthanide complexes as imaging agents anchored on nano-sized particles of boehmite†
}

\author{
Estefanía Delgado-Pinar, ${ }^{a}$ M. Teresa Albelda, ${ }^{a}$ Juan C. Frías, ${ }^{* a}$ Olga Barreiro, ${ }^{b}$ Emilio Tejera, ${ }^{b}$ \\ Vojtěch Kubíček, ${ }^{c}$ Luis J. Jiménez-Borreguero, ${ }^{b}$ Francisco Sánchez-Madrid, ${ }^{b}$ Éva Tóth, ${ }^{c}$ Javier Alarcón ${ }^{* d}$ and \\ Enrique García-España*a
}

The synthesis of boehmite nanoparticles modified with lanthanides ( $\mathrm{Eu}, \mathrm{Tb}$ and $\mathrm{Gd})$ is described. Their synthesis, characterization and in vitro assays with HeLa cells were performed. The nuclear magnetic relaxation dispersion (NMRD) profiles of the two chelating moieties were studied. Imaging data from laser scanning confocal fluorescence microscopy and flow cytometry revealed that the nanoscaffolds were taken up by the cells, distributed throughout the cytoplasm and showed no toxicity. This platform could represent an alternative to silica-based inert matrices as imaging vehicles.

\section{Introduction}

Lanthanide ions possess interesting photophysical and magnetic properties that make them very attractive as optical and magnetic resonance imaging contrast agents. They have long radiative lifetimes that fall in the range of microseconds or sub-microseconds for $\mathrm{Yb}, \mathrm{Nd}$, and milliseconds or sub-milliseconds for $\mathrm{Eu}, \mathrm{Tb}$, and $\mathrm{Sm} .{ }^{1}$ Considering that most organic chromophores have lifetimes of ca. $10 \mathrm{~ns}$, these long lifetimes are of great value in vivo as background emission, or autofluorescence, and light scattering can be excluded by simple timegating. The paramagnetic ion gadolinium $\left(\mathrm{Gd}^{3+}\right)$ has been extensively used in medicine as a contrast agent, complexed with acetate functionalized polyazamacrocycles or open-chain polyamines. ${ }^{2}$ This complexation has recently received attention due to the discovery of NSF/NFD (nephrogenic systemic fibrosis/nephrogenic fibrosing dermopathy), a disease produced by the release of free $\mathrm{Gd}^{3+}$ in patients with renal failure. ${ }^{3}$ So it is necessary then that the complexes attain extremely high kinetic and thermodynamic stability to preserve their integrity. ${ }^{4}$

Nowadays there is a considerable effort directed toward the production of nano-sized materials for bioimaging applications

aInstituto de Ciencia Molecular (ICMol), Departamento de Química Inorgánica, Universidad de Valencia, Edificio de Institutos de Paterna, C/Catedrático José Beltrán 2, Apartado de Correos 22085, 46071, Valencia, Spain.E-mail: juan.frias@uv.es; Tel: +34963544403

${ }^{b}$ Departamento de Biología Vascular e Inflamación, Centro Nacional de Investigaciones Cardiovasculares (CNIC), Melchor Fernández Almagro 3, 28029, Madrid, Spain

${ }^{c}$ Centre de Biophysique Moléculaire, CNRS, Rue Charles Sadron, 45071, Orléans Cedex 2, France

'Departamento de Química Inorgánica, Universidad de Valencia, 46100, Burjasot, Valencia, Spain

$\dagger$ Electronic supplementary information (ESI) available: boehmite functionalization, EDX, fluorescence titration, DRX, TEM. See DOI: $10.1039 / \mathrm{cldt} 10389 \mathrm{j}$ in biotechnology and medicine. Semiconductor quantum dots have been used as fluorescent probes for cell labeling in optical imaging due to their exceptional fluorescent properties, although some cytotoxicity problems have been described in in vivo studies. ${ }^{5}$ Magnetic nanoparticles have been employed as contrast agents for magnetic resonance imaging (MRI). ${ }^{6}$ These paramagnetic or superparamagnetic nanoparticles that can be coated with a polymer are already in clinical use. They possess sensitivity in the nanomolar range and can be further modified at their surface for increasing their sensitivity towards a selected target. MRI has become a powerful imaging tool for the assessment of living organisms without delivering dangerous radiation, providing remarkable anatomical resolution and physiological information. The use of paramagnetic contrast agents improves the analysis of images and facilitates their interpretation.

Multifunctional nanoparticles have shown great promise as new probes for biomedical imaging. They can not only carry large payloads of imaging agents, but can also be modified to target specific cell markers by conjugation to specific molecules (proteins, monoclonal antibodies or peptides). ${ }^{7}$ Due to the mild synthetic conditions, the sol-gel technique ${ }^{8}$ represents an appropriate route to create hybrid materials that are conveniently designed by combining a lanthanide complex with an inorganic host. ${ }^{9}$ The hybrids can show attractive properties from a mechanical and chemical point of view. The doping of the host with visible emitting lanthanides $\left(\mathrm{Eu}^{3+}, \mathrm{Tb}^{3+}\right)$ shows potential as a new way to achieve luminescent devices. On the other hand, modification of the host with gadolinium ions $\left(\mathrm{Gd}^{3+}\right)$ can afford nanoparticles with features for MR imaging. The new vehicle benefits from the fact that $\mathrm{Gd}^{3+}$ ions shorten the $T_{1}$ (spin-lattice) relaxation time, a large payload can be obtained and a larger size that slows down molecular rotation, resulting in an additional increase in the relaxivity $r_{1}$ through the increased rotational correlation time $\tau_{\mathrm{R}}$ 
The supports mostly used for preparing sensing devices are silica-based due to the good performance of molecules attached to these inert matrices. ${ }^{10}$ A further advance in this field would be to look for new supports presenting different properties from silica. In this regard, here we report on the synthesis of a new carrier based on boehmite, an aluminium oxyhydroxide $(\mathrm{AlO}(\mathrm{OH}))$ containing terminal hydroxyl groups that render high reactivity to the surface, which represents an alternative. It can be prepared as a colloidal solution providing a large surface area available for increasing the efficiency of the device. Moreover, the change of boehmite from a sol to a gel state, depending on the $\mathrm{pH}$, would provide a means for recovering the material by a simple centrifugation procedure.

\section{Results and discussion}

\subsection{Preparation and characterization of the nanoparticles}

Water-dispersible and biocompatible boehmite functionalized nanoparticles were prepared according to a reported method (Scheme 1). The tris-tert-butyl ester of DO3A was prepared under mild alkylation conditions according to Parker and coworkers. ${ }^{11}$ Reaction of the DO3A ester in $\mathrm{CH}_{3} \mathrm{CN}$ with (3iodopropyl)trimethoxysilane afforded a functionalized DO3A synthon that is anchored onto nanosized particles of boehmite. Unreacted material is separated from aluminium-DO3A triester nanoparticles by centrifugation. Hydrolysis of the tert-butyl groups of DO3A was accomplished using trifluorocacetic acid. For the preparation of DTPA derivatives, DTPA-bisanhydride was reacted with (3-aminopropyl)triethoxysilane in DMF to afford a product that is attached to the surface of boehmite. Lanthanide complexes were prepared by reaction of the supported ligands with the appropriate chloride salts. Elemental analysis provided a loading of $2.8 \times 10^{-4}, 2.2 \times 10^{-4}$ and $1.6 \times 10^{-4}$ moles of gadolinium, terbium and europium per gram of sample of DO3Aboehmite and $1.9 \times 10^{-4}, 1.9 \times 10^{-4}$ and $2.9 \times 10^{-4}$ moles per gram of DTPA-boehmite complexes of gadolinium, terbium and europium, respectively. These payload values are similar to those we have previously reported for the functionalization of boehmite nanoparticles with other organic substrates ${ }^{12}$ and correspond to a range of 800-1500 lanthanide ions per nanoparticle functionalized with DO3A and 100-300 lanthanide ions for those particles that incorporate DTPA. The shapes and sizes of the nanoparticles were observed using transmission electron microscopy (TEM). TEM images revealed highly monodisperse homogenous spherical particles with a mean size of $18 \pm 1 \mathrm{~nm}$ (Fig. 1) for particles that included the DO3A synthon and a mean size of $9 \pm 1 \mathrm{~nm}$ for particles that contained DTPA. Boehmite nanoparticles that were used for grafting DO3A and DTPA belonged to different synthetic crops. The $\mathrm{pH}$ conditions of the preparation can vary the initial size of the particles, however the grafting of the organic parts did not produce any degradation or change in the size of the nude particles.

The supported materials, LnDO3A-boehmite and LnDTPAboehmite, were checked by conventional solid state techniques. XRay powder diffractograms of Eu-, Tb- and GdDO3A-boehmite show the presence of broad peaks at $13.7^{\circ}, 28.3^{\circ}, 38.4^{\circ}, 49.2^{\circ}$ and $64.8^{\circ} 2 \theta$, which are characteristic of the boehmite structure. This result evidences that the matrix has not been disrupted throughout the grafting step and the width of the peaks confirms the small size measured by electron microscopy.

The chemical composition of the nanoparticles was analyzed using an energy-dispersive X-ray (EDX) spectrometer attached to a high-resolution scanning electron microscope. The EDX spectra of the two types of nanoparticles (based on DO3A or DTPA chelating moieties) were performed at least ten times at different spots for each sample and show the presence of silicon and either europium, terbium or gadolinium, depending on the lanthanide salt used. This method provides an average qualitative analysis of the samples with a $1: 1$ ratio of lanthanide : silicon, which supports that all the anchored material is coordinating the lanthanides.

CPMAS ${ }^{29} \mathrm{Si}$ NMR spectroscopy ${ }^{13}$ is a well established technique that allows the discrimination between the $\mathrm{M}\left(\mathrm{C}_{3}-\mathrm{SiO}\right), \mathrm{D}$ $\left(\mathrm{C}_{2}-\mathrm{SiO}_{2}\right), \mathrm{T}\left(\mathrm{C}-\mathrm{SiO}_{3}\right)$ and $\mathrm{Q}\left(\mathrm{SiO}_{4}\right)$ units. The cleavage of the $\mathrm{Si}-\mathrm{C}$ bonds of the $\mathrm{T}$ units to give the $\mathrm{Q}$ units produces an upfield shift of the ${ }^{29} \mathrm{Si}$ signal, which moves from $\delta=-40$ to $-80 \mathrm{ppm}$ (T units) to $\delta=-90$ to -110 (Q units). In this respect, the CPMAS ${ }^{29} \mathrm{Si}$ NMR in EuDO3A-boehmite presents one signal centered at $-68.0 \mathrm{ppm}$, which is in concordance with a $\mathrm{T}$ unit and according to the previous discussion, the $\mathrm{Si}-\mathrm{CH}_{2}-$ bond is preserved throughout the synthetic procedure, demonstrating the covalent attachment of the silicon derivative to the boehmite surface through $\mathrm{Si}-\mathrm{O}-\mathrm{Al}$ bonds. ${ }^{14}$

\subsection{Fluorescence studies}

Fluorescence emission spectra of the DO3A derivative supported nanoparticles were recorded after direct excitation at 355 and $396 \mathrm{~nm}$ for terbium and europium, respectively. The europiumboehmite complex showed the typical transitions from ${ }^{5} \mathrm{D}_{0}$ to ${ }^{7} \mathrm{~F}_{J}$ $(J=0,1,2,3,4)$ of europium complexes, pointing out the $\Delta J=2$ band, which is particularly sensitive to the chemical environment, it also revealed a big $\Delta J=2 / \Delta J=1$ ratio. Although a big ratio of $\Delta J=2 / \Delta J=1$ in LnDO3A derivatives suggests the presence of a ternary complex with carbonate, titration experiments under controlled conditions of Eu-boehmite $(0.1 \mathrm{mM})$ with $\mathrm{NaHCO}_{3}$ in 0.1 M HEPES, pH 7.4, $298 \mathrm{~K}$ exposed that 2 water molecules are retained and the fluorescence intensity is not quenched by the addition of $\mathrm{NaHCO}_{3}$, so no changes in the $\Delta J=2 / \Delta J=1$ ratio were observed. ${ }^{15} \mathrm{~A}$ small decrease was observed during the titration, which is due to the dilution of the sample after the addition of $\mathrm{NaHCO}_{3}$ (see ESI $\dagger$ ). The Tb-boehmite complex shows distinctive luminescence at $480-630 \mathrm{~nm}$ consisting of four emission bands, assigned to the respective transitions from the ${ }^{5} \mathrm{D}_{4}$ state to the ground state ${ }^{7} \mathrm{~F}_{J}(J=3,4,5,6)$. The number of coordinated water molecules in $\mathrm{Eu}-$ and $\mathrm{Tb}$-boehmite was assessed by measuring the lifetime of the Eu ${ }^{5} \mathrm{D}_{0}$ and $\mathrm{Tb}^{5} \mathrm{D}_{4}$ excited states in $\mathrm{H}_{2} \mathrm{O}$ and $\mathrm{D}_{2} \mathrm{O}$ by application of the modified Horrocks equation yielding a $q$ value of $2 .{ }^{16}$ For Eu- and TbDTPA-boehmite samples, the $q$ values were 1 . In general, the lanthanide complexes (such as $\mathrm{Eu}^{3+}, \mathrm{Gd}^{3+}$ and $\mathrm{Tb}^{3+}$ ) of DTPA-monoamide have a coordination number of eight for the lanthanides and have approximately one metal-bound water molecule. ${ }^{17}$

\subsection{Nuclear magnetic relaxation dispersion profiles}

In order to assess the efficacy of the nanoparticles as relaxation enhancement agents, Nuclear Magnetic Relaxation Dispersion 

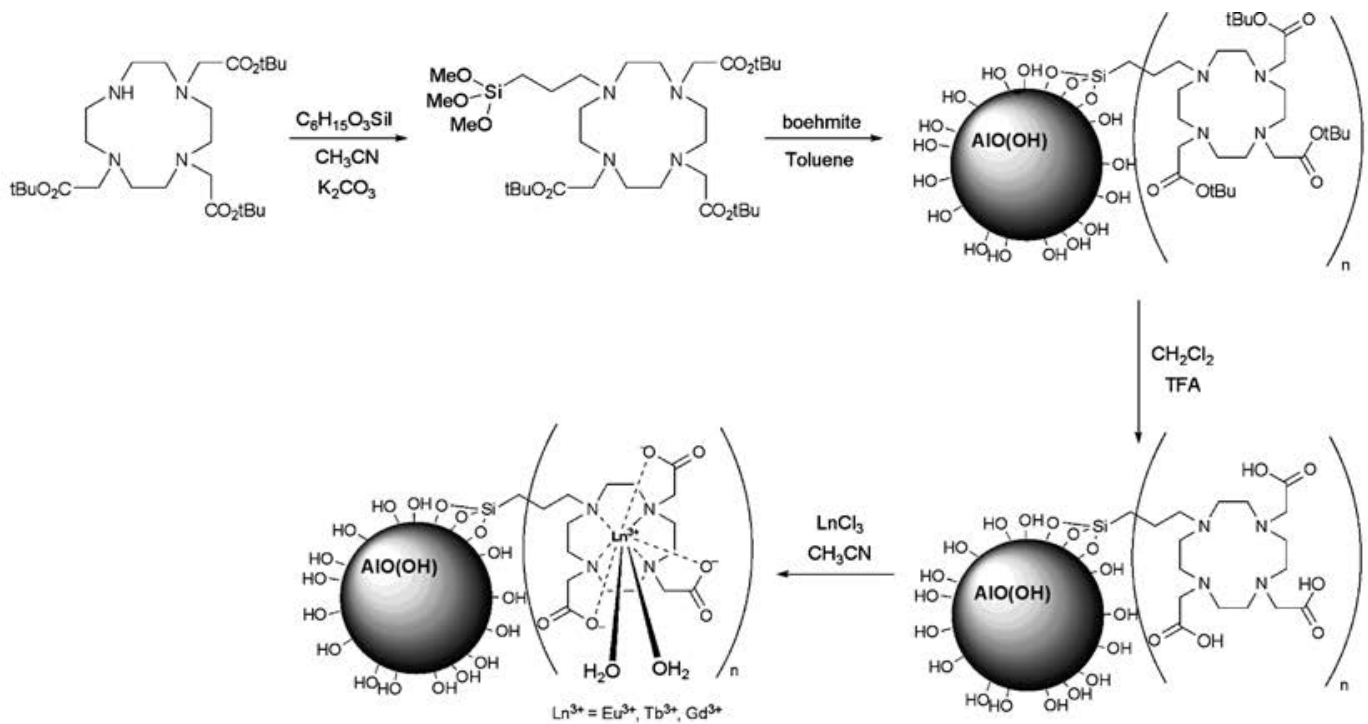

$\mathrm{LnCl}_{3}$
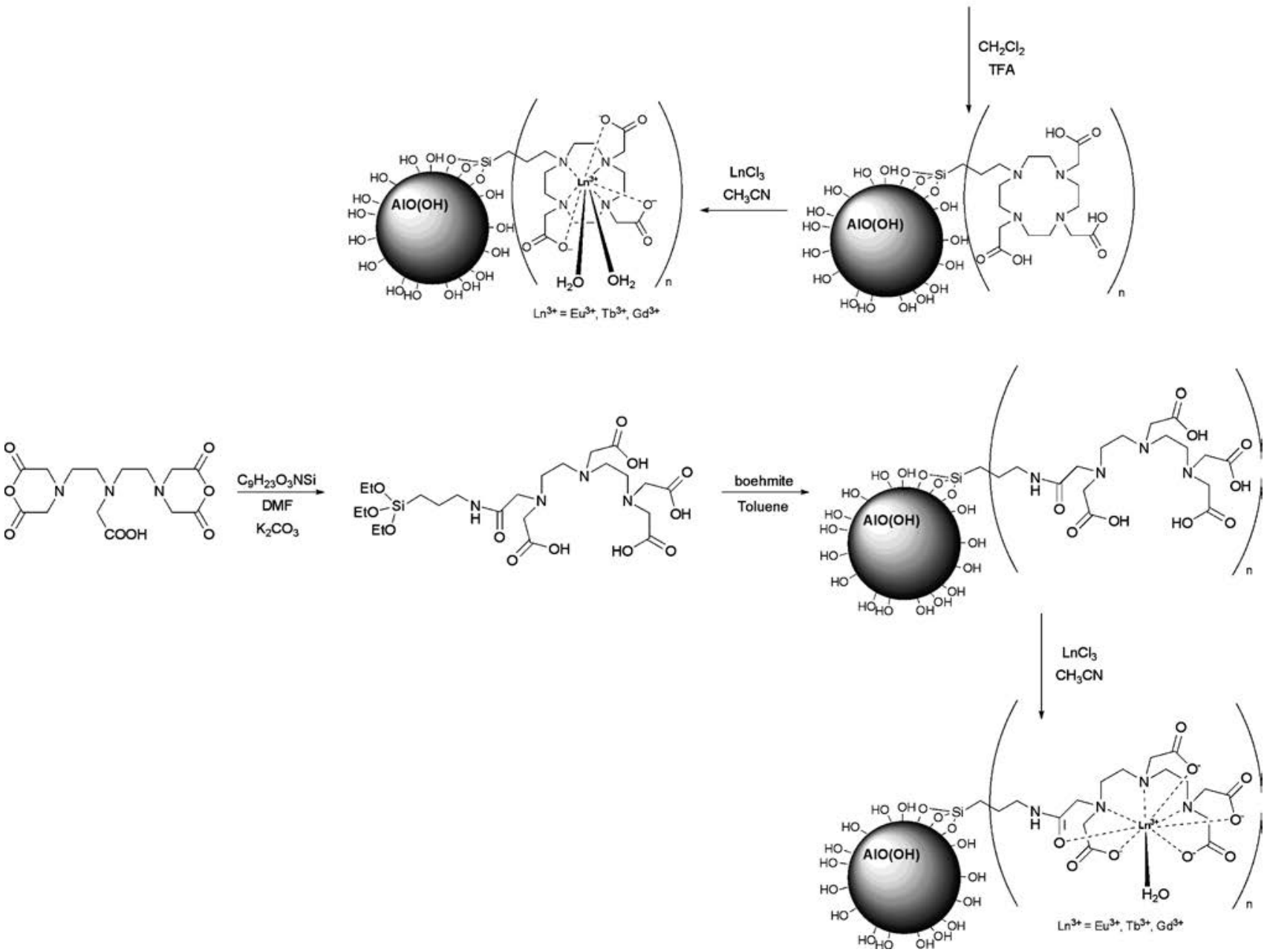

Scheme 1 Synthesis of hybrid nanoparticles.

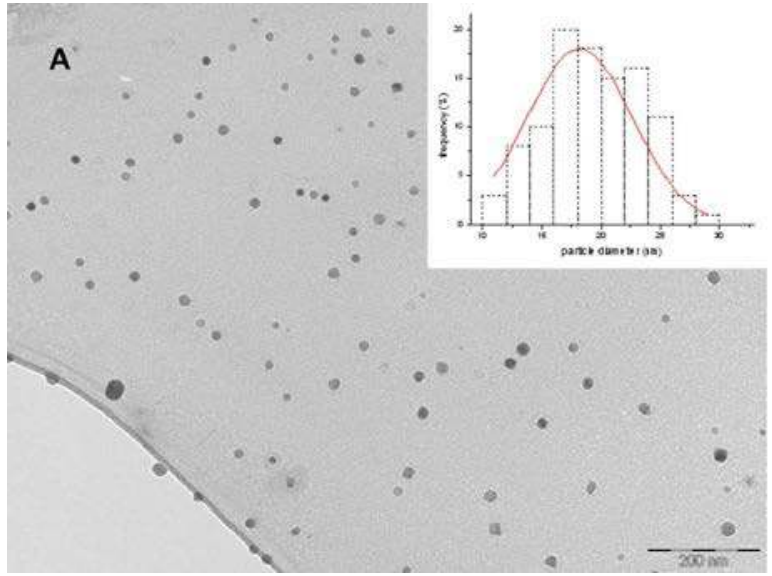

B

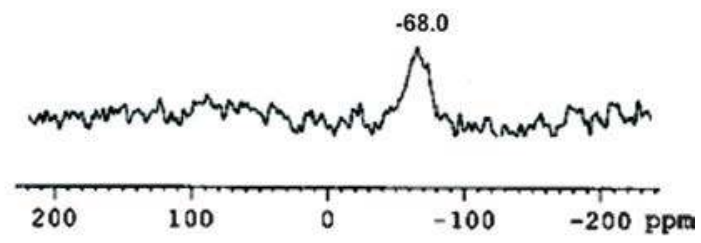

Fig. 1 A) A TEM image of GdDO3A-boehmite reveals spherical monodisperse nanoparticles. Inset shows size distribution of the nanoparticles. B) ${ }^{29} \mathrm{Si}$ NMR of EuDO3A-boehmite showing a single peak centered at $-68 \mathrm{ppm}$. 
(NMRD) profiles were recorded at $25{ }^{\circ} \mathrm{C}$ and $37{ }^{\circ} \mathrm{C}$ on both GdDO3A-boehmite and GdDTPA-boehmite systems in solutions containing a surfactant $(0.1 \%$ xanthan gum). Xanthan is often used to keep particles in solution. ${ }^{18}$ In addition, the relaxivities of the GdDTPA-boehmite were also measured after simple dispersion of the nanoparticles in water. The NMRD profiles are shown in Fig. 2 and 3. The aqueous suspension of the GdDTPA-boehmite gave considerably (around 3 times) higher relaxivity values at all magnetic fields than those obtained in the presence of xanthan (Fig. 2). This indicates that in the pure aqueous solution, the aggregation phenomenon is important, which is prevented (at least partially) in the xanthan solution by the surfactant. Interestingly, the temperature dependency is very small, in particular at higher magnetic fields, both in the presence or absence of the xanthan.

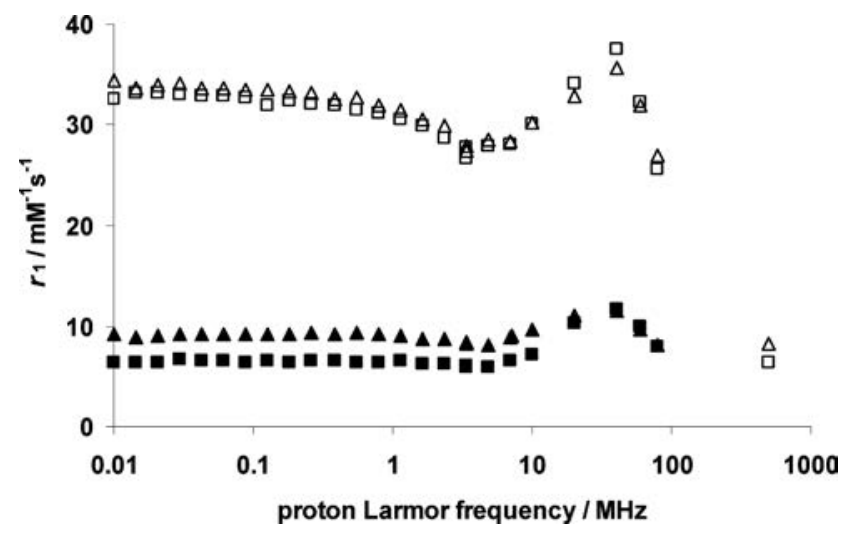

Fig. $2{ }^{1} \mathrm{H}$ NMRD profiles of GdDTPA-boehmite in aqueous suspension at $25^{\circ} \mathrm{C}(\triangle)$ and $37{ }^{\circ} \mathrm{C}(\square)$ and in $0.1 \% \mathrm{w} / \mathrm{w}$ xanthan solution at $25^{\circ} \mathrm{C}$ (ム) and $37^{\circ} \mathrm{C}(\boldsymbol{\square}) \cdot c_{\mathrm{Gd}^{3+}}=0.1 \mathrm{mM}$.

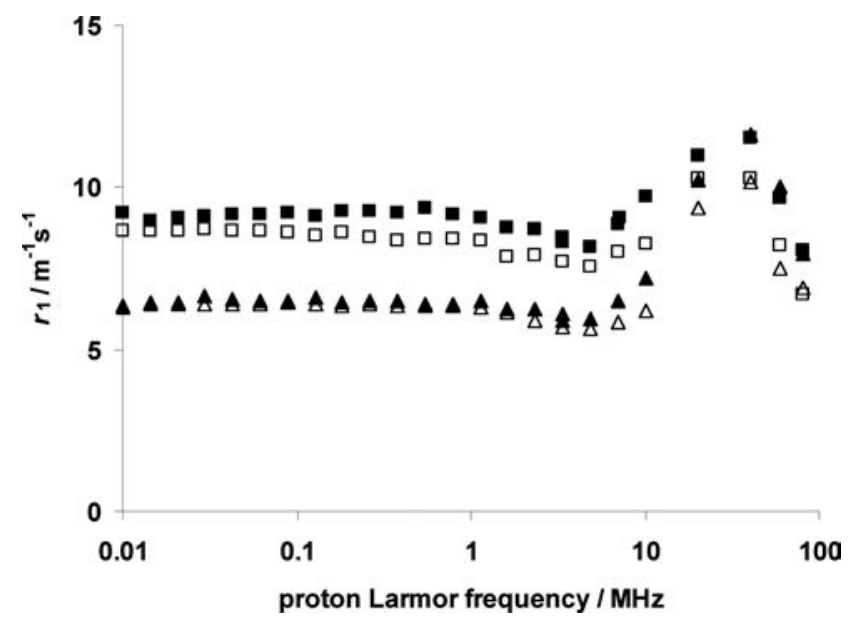

Fig. $3 \quad{ }^{1} \mathrm{H}$ NMRD profiles of GdDTPA-boehmite (filled symbols) and GdDO3A-boehmite (empty symbols) in $0.1 \% \mathrm{w} / \mathrm{w}$ xanthan solution at $25^{\circ} \mathrm{C}$ (squares) and $37^{\circ} \mathrm{C}$ (triangles). $c_{\mathrm{Gd}^{3+}}=0.1 \mathrm{mM}$.

The relaxivities measured in the xanthan solution are very similar for the two systems, despite the different chelating unit used to complex the $\mathrm{Gd}^{3+}$ and the different sizes of the particles $(18 \mathrm{~nm}$ for GdDO3A-boehmite and $9 \mathrm{~nm}$ for GdDTPA-boehmite). The small absolute values of the relaxivities are rather unexpected for such slowly rotating systems, while the form of the curves, with the high-field relaxivity hump, is characteristic of slow tumbling. Similar relaxivity profiles (both in their form and absolute values) have been previously reported for Gd-functionalized mesoporous silica particles with large pores. ${ }^{19}$ Those low molar relaxivities were rationalized by an important proportion of the $\mathrm{Gd}^{3+}$ complexes grafted inside the large pores, which do not contribute to the relaxivity. However, in our boehmite particles there are no pores, therefore we suggest that some aggregation persists in the xanthan solution, which prevents water access to the interior of the aggregates and therefore limits the proton relaxivity.

${ }^{17} \mathrm{O}$ transverse relaxation rates are often used to characterize the water exchange properties of both small molecular weight and macromolecular $\mathrm{Gd}^{3+}$-based potential MRI contrast agents. We have measured variable temperature ${ }^{17} \mathrm{O}$ transverse relaxation rates on aqueous solutions of GdDO3A-boehmite and GdDTPAboehmite with respect to reference solutions containing the diamagnetic $\mathrm{Y}^{3+}$ analogues at identical concentration and $\mathrm{pH}$. Fig. 4 shows the reduced relaxation rates, defined as $1 / T_{2 \mathrm{r}}=$ $\left(1 / T_{2}-1 / T_{2 \text { ref }}\right) / P_{\mathrm{m}}$ where $T_{2}$ and $T_{2 \text { ref }}$ are the experimental transverse relaxation rates of the $\mathrm{Gd}^{3+}$ complex and of the reference solution, respectively, and $P_{\mathrm{m}}$ is the molar fraction of the coordinated water molecule $\left(P_{\mathrm{m}}=c_{\mathrm{Gd}} \times q / 55.5\right)$. In the calculation of the $1 / T_{2 \mathrm{r}}$ data, we assumed $q=2$ and $q=1$ for GdDO3A-boehmite and GdDTPA-boehmite, respectively. Interestingly, for both systems, the relaxation rates decrease with increasing temperature throughout all the temperature range, which is indicative of fast water exchange. Some of the Gdcomplexes are likely enclosed inside the aggregates without bulk water access (see above) and therefore do not contribute to the measured relaxation rates (and their proportion changes with temperature). The complexity of the system prevents the analysis of the data to calculate the exact exchange rate constant. However, the form of the $1 / T_{2 \mathrm{r}}$ curve evidences that the complexes on the surface have fast water exchange, considerably faster than that measured for the corresponding monomers. Indeed, for the GdDO3A- ${ }^{20}$ and GdDTPA-monoamide complexes, ${ }^{21}$ the $1 / T_{2 \mathrm{r}}$ versus inverse temperature curves show an intermediate and slow exchange regime, respectively. The exact reasons for the fast water exchange are not known; we can hypothesize that the large number of $\mathrm{OH}$ groups on the surface might catalyze the exchange process.

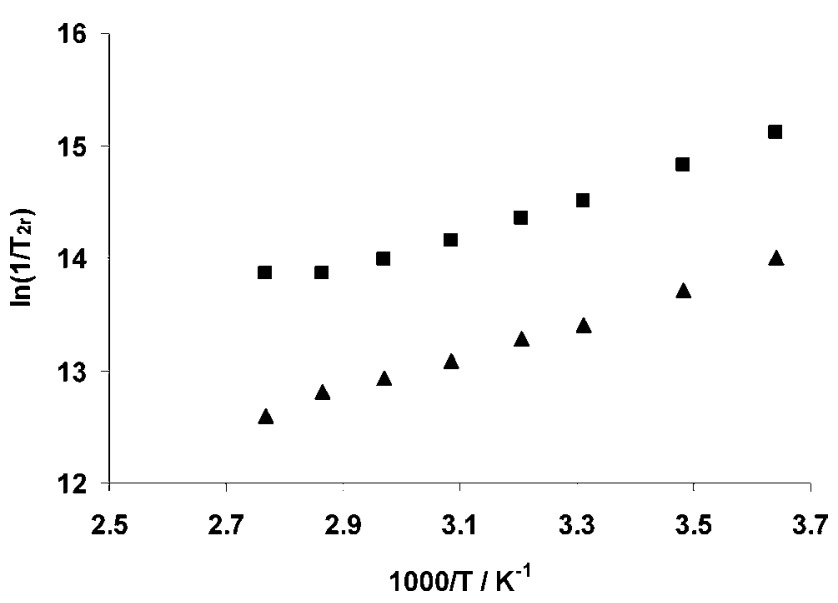

Fig. 4 Reduced ${ }^{17} \mathrm{O}$ transverse relaxation rates measured in solutions of GdDO3A-boehmite ( $(\boldsymbol{\Delta})$ and GdDTPA-boehmite $(\boldsymbol{\square})$. 


\subsection{Confocal laser scanning microscopy}

These fluorescent (Eu- and TbDO3A-boehmite) nanoparticles were tested as imaging contrast agents for in vitro applications. Human HeLa cells were incubated with the europium or terbium hybrid nanoparticles. After $4 \mathrm{~h}$ of incubation with a $100 \mu \mathrm{M}$ concentration of lanthanide nanoparticles, confocal laser scanning microscopy clearly indicated uptake of the material by HeLa cells. The lanthanide particles appear evenly distributed throughout the cytoplasm, apparently not being included in vesicles. The membrane staining CD44 antibody was useful to assess the cellular incorporation of lanthanide particles, as depicted in the orthogonal sections from Fig. 5. The concentration and incubation time used for the experiment did not produce cellular toxicity, as assessed by checking the morphology of the cells by microscopy.

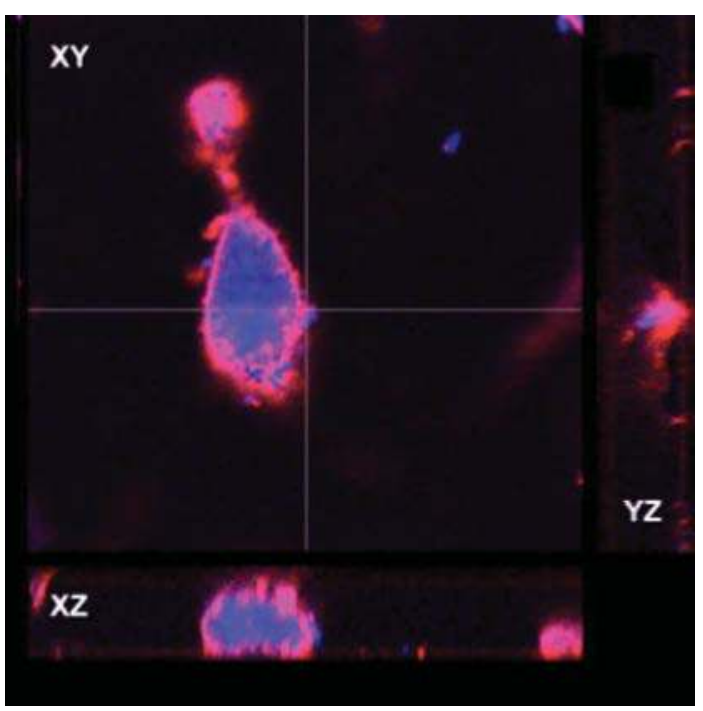

Fig. 5 Laser scanning confocal fluorescence microscopy of HeLa cells showing, at different planes, uptake of the nanoparticles located in the cytoplasm. Red, CD44; blue, boehmite functionalized nanoparticles.

\subsection{Flow cytometry}

Flow cytometry analysis was performed on HeLa cells incubated with the lanthanide nanoparticles $(100 \mu \mathrm{M})$ for the same period that cells were incubated for confocal microscopy (Fig. 6). Selected gate regions result in four quadrants: Q1, necrotic; Q2, late apoptotic; Q3, early apoptotic; and Q4, viable cells. The data from Fig. $6 \mathrm{a}$ and $6 \mathrm{~b}$ show that the effect of the lanthanide modified boehmite on the HeLa cells is negligible, since similar values are obtained for incubated cells and non-incubated cells. More than $86 \%$ of the cells are viable, no matter the chelate unit chosen.

\section{Conclusion}

In summary, we have reported on the surface modification of an aluminium oxyhydroxide support with different lanthanide chelates for MR or optical imaging by an easy one-pot procedure. The loadings attained by the nanoparticles provide a magnification of the signal for MRI, which could be useful to image small structures, such as cells. NMRD profiles showed the typical hump at high-fields of slowly rotating systems, while ${ }^{17} \mathrm{O}$ transverse relaxation rates reflect a fast water exchange process. We have also evaluated the optical properties in human HeLa cells. The nanoparticles are taken up and localize all over the cytoplasm of the cells and do not produce cellular toxicity, as flow cytometry analysis reveals.

\section{Experimental}

The preparation of nanosized boehmite particles involved two steps. The first one was the hydrolysis of aluminium secbutoxide $\left(\mathrm{AlOBu}^{s}\right.$, from Aldrich) in an excess of water at $80{ }^{\circ} \mathrm{C}$ under vigorous stirring. After the alkoxide addition, an exothermic reaction took place and a gel was formed almost immediately, which was held under stirring for several hours. The second step was peptisation that was carried out by keeping the boehmite particles in a nitric acid solution at $90{ }^{\circ} \mathrm{C}$ for 1 week. ${ }^{10 a}$

The $1 / T_{1}$ nuclear magnetic relaxation dispersion (NMRD) profiles of the $\mathrm{Gd}^{3+}$ complexes were recorded on a Stelar SMARtracer FFC fast-field-cycling relaxometer covering magnetic fields from $2.35 \times 10^{-4} \mathrm{~T}$ to $0.25 \mathrm{~T}$, which corresponds to a proton Larmor frequency range of $0.01-10 \mathrm{MHz}$. The relaxivity at higher fields was recorded using a Bruker WP80 adapted to variable field measurements and controlled by the SMARtracer PC-NMR console. The temperature was controlled by a VTC90 temperature control unit and fixed by a gas flow. The temperature was determined according to previous calibration with a $\mathrm{Pt}$ resistance temperature probe. NMRD profiles were recorded in solutions containing $0.1 \%(\mathrm{w} / \mathrm{w})$ xanthan gum $\left(0.1 \mathrm{mM} \mathrm{Gd}^{3+}\right.$, pH 7.4 in 0.02 M HEPES buffer). For GdDTPA-boehmite, we also measured relaxivities in aqueous suspension of the nanoparticles $\left(\sim 1 \mathrm{mM} \mathrm{Gd}^{3+}, \mathrm{pH} 7\right)$. Following sonication, this aqueous suspension remains stable for $\sim 30$ mins when sedimentation starts to appear. The solutions containing the xanthan gum are stable and give reproducible relaxivities for an extended period of time.

Variable temperature ${ }^{17} \mathrm{O}$ NMR transverse $\left(T_{2}\right)$ relaxation time measurements were carried out on a Bruker Avance 500 spectrometer in aqueous solutions of the $\mathrm{Gd}^{\mathrm{III}}$ complexes. They were referenced to a solution containing the same nanoparticle at identical concentration and $\mathrm{pH}$ where the $\mathrm{Gd}^{3+}$ ions were replaced by the diamagnetic $\mathrm{Y}^{3+}$. Transverse ${ }^{17} \mathrm{O}$ relaxation times $\left(T_{2}\right)$ were obtained by the Carr-Purcell-Meiboom-Gill spin-echo technique. ${ }^{22}$ To improve sensitivity in ${ }^{17} \mathrm{O}$ NMR, ${ }^{17} \mathrm{O}$-enriched water $\left(10 \% \mathrm{H}_{2}{ }^{17} \mathrm{O}\right.$, Cortecnet) was added to the solutions to yield around $1 \%{ }^{17} \mathrm{O}$ enrichment. The temperature was calculated according to previous calibration with ethylene glycol and methanol. ${ }^{23}$ The concentration of the samples was $\sim 1 \mathrm{mM}$ in $\mathrm{Gd}^{3+}$, $\mathrm{pH}=7$.

Human HeLa cells were seeded on glass coverslips and grown in DMEM (Sigma Chemical Co.; St Louis, MO) supplemented with $10 \%$ fetal bovine serum (Linus, Spain), $4.5 \mathrm{~g} \mathrm{~L}^{-1}$ glucose, L-glutamine, $500 \mathrm{U} \mathrm{mL}^{-1}$ penicillin/streptomycin and $20 \mathrm{mM}$ HEPES (Biowhitaker, Walkersville, MD). When confluence was reached, monolayers were incubated with a suspension of fresh medium containing $100 \mu \mathrm{M}$ of europium or terbium particles for $4 \mathrm{~h}$. Then, coverslips were extensively washed and fixed with $4 \%$ paraformaldehyde in PBS. Immunofluorescence staining was performed as previously described. ${ }^{24}$ Anti-CD44 (HP2/9) (a cell-surface glycoprotein involved in cell-cell interactions, cell 
(a)
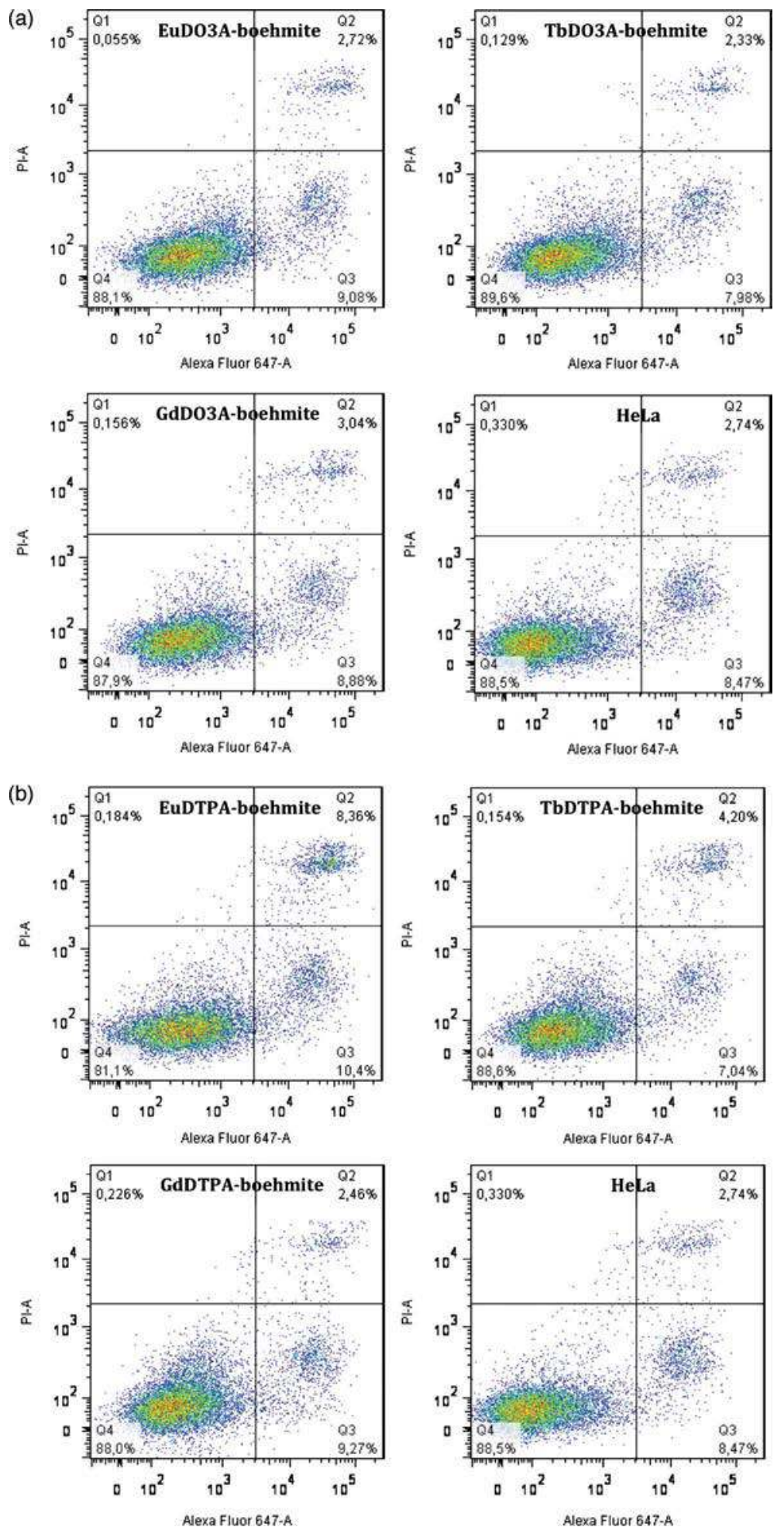

Fig. 6 Flow cytometry data for HeLa cell membrane permeability to propidium iodide versus Annexin-V Alexa Fluor 647. (a) Boehmite LnDO3A derivatives. (b) Boehmite LnDTPA derivatives.

adhesion and migration), generated in our laboratory at CNIC, was used as the primary antibody. Goat anti-mouse Alexa 647 (Molecular Probes, Invitrogen, Carlsbad, CA) was employed as the secondary antibody. Next, samples were mounted using Prolong (Molecular Probes). Series of optical sections were obtained with a
Leica TCS-SP5 confocal laser scanning unit (Leica Microsystems, Heidelberg, Germany), using a $63 \times$ oil immersion objective (NA 1.4), a $405 \mathrm{~nm}$ diode for the nanoparticles excitation and a $633 \mathrm{~nm}$ laser line for Alexa 647 visualization. Images were analyzed using Leica Confocal Software. 
Human HeLa cells were cultured and incubated with lanthanides as described above. Then, cells were trypsinized and washed in PBS, followed by incubation with annexin-V Alexa 647 (Molecular Probes) for $15 \mathrm{~min}$ at room temperature. Finally, propidium iodide was added to a final concentration of $0.001 \%$ and samples were analyzed in a flow cytometer (FACSCanto ${ }^{\mathrm{TM}}$ II, BD Biosciencies). Cells were subdivided into 4 categories: negative for both stainings (viable), positive for annexin $\mathrm{V}$ (early apoptotic), double positive (late apoptotic) and only positive for propidium iodide (necrotic).

\section{Acknowledgements}

We are grateful for financial support from CTQ2009-14288CO4-01 and European FEDER funds. E. D-P wants to thank MCINN for a predoctoral FPU fellowship, M. T. A. thanks Ministerio de Educación y Ciencia of Spain for a Juan de la Cierva contract, J. C. F. thanks Ayuntamiento de Valencia for the Carmen y Severo Ochoa Fellowship. We want to thank Zoltan Palinkas for the relaxivity measurements.

\section{References}

1 (a) E. G. Moore, A. P. S. Samuel and K. N. Raymond, Acc. Chem. Res., 2009, 42, 542; (b) C. P. Montgomery, B. S. Murray, E. J. New, R. Pal and D. Parker, Acc. Chem. Res., 2009, 42, 925; (c) T. Gunnlaugsson and J. P. Leonard, Chem. Commun., 2005, 3114; (d) J.-C. G. Bunzli, Acc. Chem. Res., 2006, 39, 53.

2 (a) The Chemistry of Contrast Agents in Medical Magnetic Resonance Imaging, ed. A. E. Merbach and E. Toth, 1st edn, Wiley, New York, 2001; (b) P. Caravan, J. J. Ellison, T. J. McMurry and R. B. Lauffer, Chem. Rev., 1999, 99, 2293; (c) P. Caravan, Chem. Soc. Rev., 2006, 35, 512; (d) P. Hermann, J. Kotek, V. Kubicek and I. Lukes, Dalton Trans., $2008,3027$.

3 C. Thakral, J. Alhariri and J. L. Abraham, Contrast Media Mol. Imaging, 2007, 2, 199.

4 (a) A. Bianchi, L. Calabi, F. Corana, S. Fontana, P. Losi, A. Maiocchi, L. Paleari and B. Valtancoli, Coord. Chem. Rev., 2000, 27, 19; (b) F. K. Kalman, Z. Baranyai, I. Toth, I. Banyai, R. Kiraly, E. Brucher, S. Aime, X. Sun, A. D. Sherry and Z. Kovacs, Inorg. Chem., 2008, 47, 3851.

5 (a) A. P. Alivisatos, W. W. Gu and C. Larabell, Annu. Rev. Biomed. Eng., 2005, 7, 55; (b) F. Pinaud, X. Michalet, L. A. Bentolia, M. J. Tsay, S. Doose, J. J. Li, G. Iyer and S. Weiss, Biomaterials, 2006, 27, 1679.

6 (a) S. Aime, D. Delli Castelli, S. Geninatti Crich, E. Gianolio and E. Terreno, Acc. Chem. Res., 2009, 42, 822; (b) J. Gao, H. Gu and B. Xu, Acc. Chem. Res., 2009, 42, 1097; (c) J. S. Kim, W. J. Rieter, K. M. L. Taylor, H. An, W. Lin and W. Lin, J. Am. Chem. Soc., 2007, 129, 8962; (d) W. J. Rieter, J. S. Kim, K. M. L. Taylor, H. An, W. Lin, T. Tarrant and W. Lin, Angew. Chem., Int. Ed., 2007, 46, 3680.
7 (a) S. A. Corr, A. O'Byrne, Y. K. Gun'ko, S. Ghosh, D. F. Brougham, S. Mitchell, Y. Volkov and A. Prina-Mello, Chem. Commun., 2006, 4474; (b) V. P. Torchilin, Adv. Drug Delivery Rev., 2006, 58, 1532.

8 (a) C. J. Brinker, G. W. Scherer, Sol-Gel Science: The Physics and Chemistry of Sol-Gel Processing, Academic Press, New York, 1990; (b) R. J. P. Corriu and D. Leclerq, Angew. Chem., Int. Ed. Engl., 1996, 35, 1420 .

9 (a) E. Delgado-Pinar, J. C. Frías, L. J. Jimenez-Borreguero, M. T. Albelda, J. Alarcón and E. García-España, Chem. Commun., 2007, 3392; (b) K. M. L. Taylor and W. J. Lin, J. Mater. Chem., 2009, 19, 6418; (c) L. Armelao, G. Bottaro, S. Quici, M. Cavazzini, M. C. Raffo, F. Barigelletti and G. Accorsi, Chem. Commun., 2007, 2911; (d) S. Blair, R. Kataky and D. Parker, New J. Chem., 2002, 26, 530.

10 (a) R. Aucejo, J. Alarcón, C. Soriano, M. C. Guillem, E. García-España and F. Torres, J. Mater. Chem., 2005, 15, 2920; (b) J. El Haskouri, S. Cabrera, C. J. Gómez-García, C. Guillem, J. Latorre, A. Beltrán, D. Beltrán, M. D. Marcos and P. Amorós, Chem. Mater., 2004, 16, 2805.

11 S. Aime, A. Barge, M. Botta, J. A. K. Howard, R. Kataky, M. P. Lowe, J. M. Moloney, D. Parker and A. S. de Sousa, Chem. Commun., 1999, 1047.

12 R. Aucejo, P. Díaz, E. García-España, J. Alarcón, E. Delgado-Pinar, F. Torres, C. Soriano and M. C. Guillem, New J. Chem., 2007, 31, 44.

13 G. Engelhardt, D. Michel, High-Resolution Solid-State NMR of Silicates and Zeolites, Wiley, Chichester, 1987.

14 (a) J. Jiao, S. Altwasser, W. Wang, J. Weitkamp and M. Hunger, J. Phys. Chem. B, 2004, 108, 14305; (b) S. Ek, E. I. Iiskola, L. Niinistö, J. Vaittinen, T. T. Pakkanen and A. Root, J. Phys. Chem. B, 2004, 108, 11454.

15 (a) J. I. Bruce, R. S. Dickins, L. J. Govenlock, T. Gunnlaugsson, S. Lopinski, M. P. Lowe, D. Parker, R. D. Peacock, J. J. B. Perry, S. Aime and M. Botta, J. Am. Chem. Soc., 2000, 122, 9674; (b) Y. Bretonniere, M. J. Cann, D. Parker and R. Slater, Org. Biomol. Chem., 2004, 2, 1624.

16 (a) A. Beeby, I. M. Clarkson, R. S. Dickins, S. Faulkner, D. Parker, L. Royle, A. S. de Sousa, J. A. G. Williams and M. Woods, J. Chem. Soc., Perkin Trans. 2, 1999, 493; (b) W. D. Horrocks and D. R. Sudnick, J. Am. Chem. Soc., 1979, 101, 334.

17 (a) K. Hanaoka, K. Kikuchi, H. Kojima, Y. Urano and T. Nagano, J. Am. Chem. Soc., 2004, 126, 12470; (b) D. Parker and J. A. G. Williams, J. Chem. Soc., Dalton Trans., 1996, 3613; (c) M. Li and P. R. Selvin, J. Am. Chem. Soc., 1995, 117, 8132.

18 (a) C. Platas-Iglesias, L. Vander Elst, W. Zhou, R. N. Muller, C. F. G. C. Geraldes, T. Maschmeyer and J. A. Peters, Chem.-Eur. J., 2002, 8, 5121; (b) G. A. Pereira, D. Ananias, J. Rocha, V. S. Amaral, R. N. Muller, L. Vander Elst, É. Toth, J. A. Peters and C. F. G. C. Geraldes, J. Mater. Chem., 2005, 15, 3832.

19 F. Carniato, L. Tei, W. Dastru, L. Marchese and M. Botta, Chem. Commun., 2009, 1246.

20 E. Toth, O. M. Ni Dhubhghaill, G. Besson, L. Helm and A. E. Merbach, Magn. Reson. Chem., 1999, 37, 701.

21 E. Tóth, L. Burai, E. Brücher and A. E. Merbach, J. Chem. Soc., Dalton Trans., 1997, 1587.

22 S. Meiboom and D. Gill, Rev. Sci. Instrum., 1958, 29, 688.

23 D. S. Raiford, C. L. Fisk and E. D. Becker, Anal. Chem., 1979, 51, 2050.

24 O. Barreiro, M. Yañez-Mo, M. Sala-Valdes, M. D. Gutierrez-Lopez, S. Ovalle, A. Higginbottom, P. N. Monk, C. Cabañas and F. SanchezMadrid, Blood, 2005, 105, 2852. 